\title{
Disentangling the scarcity of near-natural Iberian hydrological resources since 1980s: a multivariate-driven approach
}

Amar Halifa-Marín ${ }^{1}$, Miguel A. Torres-Vázquez ${ }^{1}$, Enrique Pravia-Sarabia ${ }^{1}$, Marc Lemus-Cánovas ${ }^{2}$, Juan Pedro Montávez ${ }^{1}$, Pedro Jiménez-Guerrero ${ }^{1}$

$5 \quad{ }^{1}$ Regional Atmospheric Modelling (MAR) Group, Regional Campus of International Excellence Campus Mare Nostrum (CEIR), University of Murcia, 30100 Murcia, Spain.

${ }^{2}$ Climatology Group, Department of Geography, University of Barcelona, 08001 Barcelona, Spain.

Correspondence to: Pedro Jiménez-Guerrero (pedro.jimenezguerrero@um.es)

\section{Abstract}

A significant abrupt decrease of Winter Precipitation (WP) has been noticed in the Iberian Peninsula since 1980s related to atmospheric drivers. This contribution assesses the long-term variability of water

15 resources based on a multivariate-driven approach. For this purpose, the novel dataset of Near Natural Water Inflows to Reservoirs of Spain (NENWIRES) was created. Results confirm that Winter Water Inflows (WWI) have been modulated by the sudden decline in WP. These drastic reductions of WP/WWI were mainly controlled by the enhancement of the positive phase of the North Atlantic Oscillation $(\mathrm{NAOi}+)$. Nonetheless, our results also highlight the anthropogenic/physical causes contributing to the

20 1980s shift in the hydroclimate series. The rise of temperature, the cropland abandonment and forest extension provoked evapotranspiration gains and run-off weakening. NENWIRES most humid catchments registered the decrease of WWI promoted by NAOi+ persistence/frequency, while the land greening-up and ET rises explain the WWI losses in the Iberian semiarid environments. This contribution sheds some light on the recent debate about magnitude/drivers of streamflow declining over southern

25 Europe. Therefore, it might help water planning with the goal of mitigating the climate change impacts affecting the water cycle. 


\section{Introduction}

Droughts and floods keep increasing their importance as global hydroclimate hotspots under the context of climate change and its impacts on the water cycle. The Mediterranean region shows the strongest and the most consistent pattern of significant streamflow declining worldwide, highlighting an overall reduction of streamflow (Gudmundsson et al., 2021). Presently, the freshwater scarcity poses an incipient risk in the Mediterranean basin (Tramblay et al., 2020). In addition, a higher persistence/occurrence of recurrent droughts coexists with the high population density and the increase of intensive water requirements in the region (Polade et al., 2017). Water planning thus faces the challenge of securing the sustainability of ecosystems and human societies for the near future. Current hydrological studies must contribute to shed light on the hydrological resources variability/modelling based on multivariate approaches (Teuring et al., 2019, Massei et al., 2020).

Focusing on the Iberian Peninsula (IP), this territory is an ideal benchmark to study the vulnerability of

40 freshwater in response to a warmer climate. The IP is one of the most populated regions in Europe, where water requirements keep increasing. Also, the Iberian flow regimes are controlled by largely differing climate conditions. This region thus helps to assess the global warming impacts to a wide variety of hydroclimate areas. The scientific literature generally detects the Iberian streamflow declining through the last decades (e.g., Lorenzo-Lacruz et al., 2012). Nevertheless, the role of physical/anthropogenic

45 factors driving the rise of water scarcity is still under debate. The essential role of climate drivers was widely reported (Gudmundsson et al., 2021), but human-induced land cover changes, environmental policies and water planning were also highlighted (Vicente-Serrano et al., 2019). The Iberian Water Resources have been linked to meteorological droughts promoted by the decline of Winter Precipitation (WP) (Lorenzo-Lacruz et al., 2013). In addition, the robustness (significance) of recent WP decreases has

50 been confirmed by the literature (e.g., de Luis et al., 2010). These gradual WP reductions were reasonably associated to large-scale atmospheric patterns (Trigo et al., 2004). Nonetheless, Guerreiro et al. (2014) pointed out the abrupt decreases of WP within the Tagus Basin since the 1980s. They thus discussed whether WP losses were connected to a gradual decline or an abrupt shift. Furthermore, other works also quantified the same drastic reduction of WP in the surrounding watershed (Gómez-Martínez et al., 2018, 
55 Halifa-Marín et al., 2021). The potential propagation of these WP losses was not fully assessed in most of Iberian Hydrological Basins (IHB). As far as the authors are concerned, only Gómez-Martínez et al. (2018) have preliminary stated the significant abrupt decrease of streamflow in the Jucar Basin since the early 1980s. Their results might suggest that the sudden fall of water resources could have occurred in other Mediterranean or IP areas. Meanwhile, an abrupt increase of precipitation/streamflow was reported

60 for northern Europe (Stahl et al., 2010, Hannaford et al., 2013).

The opposite pattern of hydroclimate trends in Europe has been attributed to the North Atlantic Oscillation (NAOi) variability (Hannaford et al., 2013, Gómez-Martínez et al., 2018, Halifa-Marín et al., 2021). The wintertime positive phase of the NAOi (NAOi+) suddenly increased its frequency/persistence since

65 1979/1980. Some works have described the NAOi+ enhancement (e.g., Luo \& Gong, 2006, Wang et al., 2014), but uncertainties about their dynamical drivers persists up to date. Nonetheless, the NAOi+ enhancement has promoted WP gains(losses) over northern(southern) Europe (Hannaford et al., 2013, Halifa-Marín et al., 2021). In addition, the scientific literature also points to the role of evapotranspiration gains in the analysis of the decline of Mediterranean/IP water resources. Generally, the increase of water stress in the Mediterranean was linked to the increase(decrease) of evapotranspiration(precipitation). Vicente-Serrano et al. (2014) concluded that the increase of meteorological droughts was exacerbated by the temperature rise in the IP. Similar conclusions were obtained for the Mediterranean basin (GarcíaRuiz et al., 2011) and Europe (Teuling et al., 2019). All these works highlighted the role of afforestation processes into the rise of potential evapotranspiration (ETP). Peña-Angulo et al. (2021) suggested that the

75 human-induced afforestation in the IP through the $20^{\text {th }}$ Century contributed to the increase of drought severity/persistence in the IHB. García-Ruiz et al. (2011) had already described the Mediterranean land greening-up processes, which was linked to the streamflow declining. In addition, Lorenzo-Lacruz et al. (2012) associated the streamflow changes with the construction of dams. Lorenzo-Lacruz et al. (2013) described the time-lag in the response of near-natural watershed caused by the permeability of soils.

Furthermore, whereas several works concluded that forcing/natural climate variability explains the streamflow trends in the Mediterranean/IP (Gómez-Martínez et al., 2018, Gudmundsson et al., 2021), 
other authors inferred that the climate signal is relatively small in comparison to non-climatic factors (García-Ruiz et al., 2011, Teuling et al., 2019, Vicente-Serrano et al., 2019). Therefore, noticeable

85 divergences are found in the state-of-art regarding the contribution of anthropogenic/physical drivers that modulate the Iberian Water Resources. Therefore, there is a strong need for further analysis on this topic to ensure an efficient water management over the target area. Given that anthropogenic impacts are frequent worldwide, the assessment of water resources needs to focus on near-natural catchments (Stahl et al., 2010, Hannaford et al., 2013, Vicente-Serrano et al., 2014), reducing the uncertainties added by

90 human-induced impacts. Also, it allows to understand the natural hydrological response changes in the warmer climate.

Under this umbrella, this work thus aims at assessing the variability of Iberian Water Resources during the last decades (1952/2018). For that purpose, we identify/focus on reservoirs where its water inflows nearly keep the natural flow regime. As secondary goals, this contribution aims at: 1) Attributing the main driver affecting to the water inflows in the IHB; 2) Analysing the potential propagation of the WP declining to the water resources since the early 1980s; 3) Improving the knowledge about the confluence of physical/anthropogenic drivers into the hydrological response in the Mediterranean or Iberian context. For that, our initial working hypothesis is that the WP reductions mainly controlled the water scarcity 100 since 1980s, whereas it was spurred by the human-induced land cover changes.

\section{Data and Methods}

\subsection{Data Sources}

\subsubsection{Near-Natural Water Inflows to Spanish Reservoirs}

The identification of the number of reservoirs where their water inflows keep the near-natural regime 105 comes from the Historical Hydrological Data of the Spanish Ministry of Environment. This national hydrological repository includes 376 series of monthly water inflows recharging the reservoirs network. These hydrological series can be downloaded in XML format accessible through the MITECO Website (CEDEX, 2021). We collected 36 water inflow series $(9.6 \%)$ from the total repository. Then, the NEar- 
Natural Water Inflows to REservoirs of Spain (NENWIRES) dataset was created. The NENWIRES

110 dataset provides near-natural water inflows series spread throughout the peninsular territory of Spain (Fig. 1). Also, the boundaries of catchments draining to the NENWIRES reservoirs can be downloaded from the IDE (2021), which provides the area of Spanish principal/secondary basins. Only the smaller territories of Canary/Balearic Islands, Galician, Catalonian, and Andalusian Basins were not studied. Given that the headwaters of several transboundary IHB (Douro, Tagus, Guadiana) are in the Spanish 115 territory, our findings represent properly the variability of Iberian Water Resources.
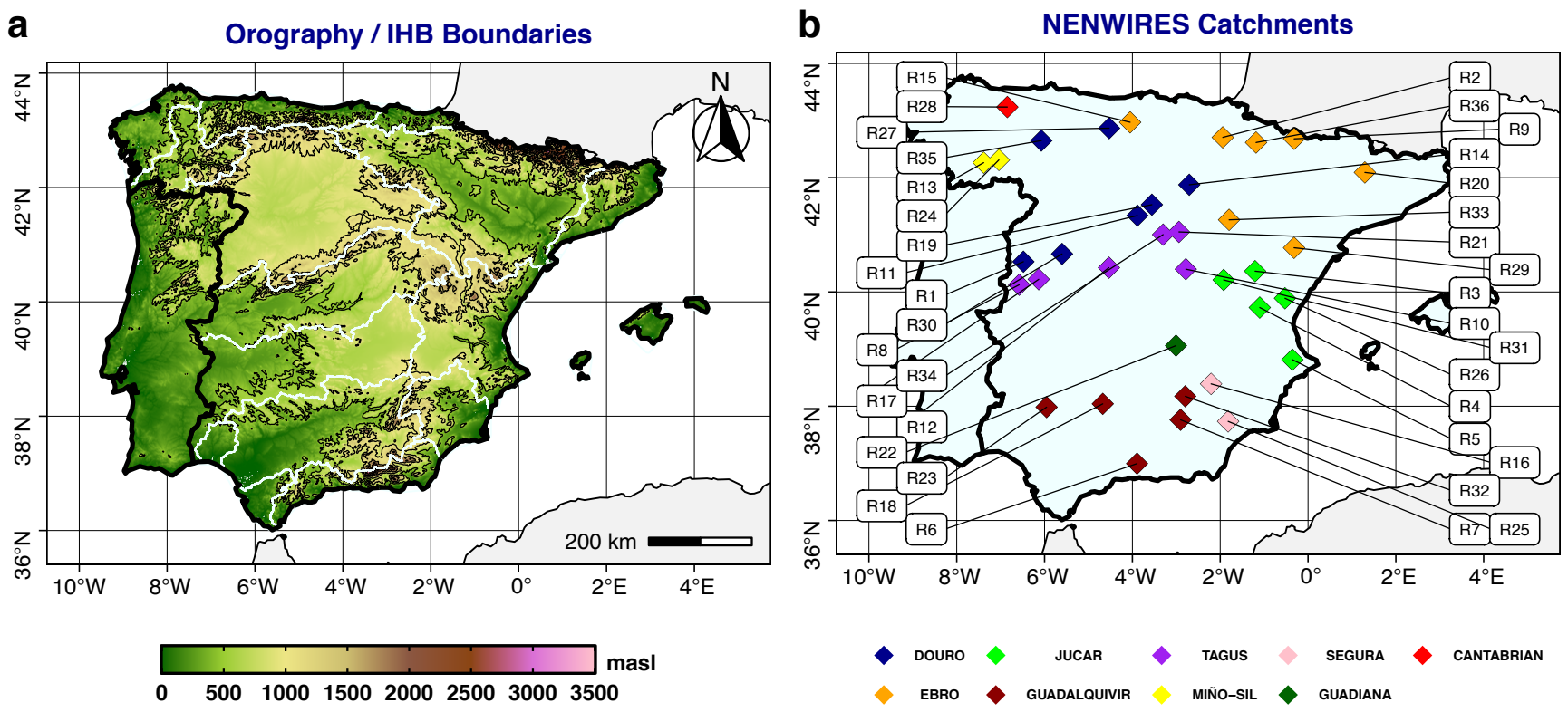

Figure 1. (a) The orography in the Iberian Peninsula (IP); and (b) the NENWIRES reservoirs grouped by the Iberian Hydrological Basins (IHB). Purple regions represent the IHB boundaries within the Spanish territory. Soft black contours represent the altitude each 500 meters above sea level.

The procedures to identify the NENWIRES catchments are summarized as: 1) we verify that water inflows are not affected by human-induced disturbances. We thus checked that upstream water inflows are not impacted by dams, channels or other water works. However, some dams related to flood risk control or hydropower production were included because they do not disturb the monthly/seasonal 
variability; 2) Long-term series are needed to conclude significantly statistical findings, so water inflows records must cover at least 45 years through the period 1952/2018; and 3) In addition, water inflow series must provide continuously records for at least 30 years. Thus, missing values should be unusual.

\subsubsection{Climate Data}

The Spanish Precipitation Gridded Dataset has been created by the Spanish Meteorological Agency (AEMET). The interpolation procedures manage 3,236 gauges. This dataset currently covers the period from January 1951 to December 2020 at daily scale. Its spatial resolution reaches $\sim 5 \mathrm{~km}^{2}$, covering the Spanish territory except the Canary Islands. The robustness of the analysis improves due to the number

135 of observational series interpolated, and the spatial high-resolution. The Temperature Gridded Dataset of Spain has technical characteristics similar to those of the precipitation dataset aforementioned. In this case, the interpolation manages 1,800 gauges. The temperature dataset provided maximum (TX) and minimum temperature (TN) at daily scale. Both datasets can be downloaded in netCDF format accessible through the AEMET Website (AEMET, 2021). One the other hand, the NCEP/NCAR Reanalysis 1 has

140 been used in many meteorological studies, providing $1 \times 1^{\circ}$ global climate data framed between $90^{\circ} \mathrm{N} / \mathrm{S}$ latitude. The high quality of this reanalysis dataset in the northern hemisphere is due to the high density of the meteorological observations worldwide. The temporal coverage ranges from January 1948 to nearly real-time. We used the monthly-averaged data of several variables: sea level pressure (SLP), geopotential height at $500 \mathrm{mb}$ (Z500), and U-V wind components (U-V Wind). NCEP/NCAR datasets were

145 downloaded from the NOAA/PSL Website (PSL, 2021). In addition, the montly NAOi was taken from the National Oceanic and Atmospheric Administration (NOAA), which covers the period from January 1950 to nearly real-time (NOAA, 2021).

\subsubsection{Soils Permeability}

The Permeability of Soils Dataset provided by the Spanish Geological Survey (IGME) was used in this contribution. It classifies soils into 9 (4) types (groups): 1) A1 and A2 represent alluvial deposits and colluvial soils formed by very permeable porous banks; 2) B1 and B2 represent carbonate bedrock, which 
are very permeable due to cracking or karstification processes; 3) $\mathrm{C} 1, \mathrm{C} 2$ and $\mathrm{C} 3$ represent well-drained volcanic soils, which are not common; and 4) D1 and D2 represent respectively low permeability and impermeable conditions. In this study, Permeable Soils include A1/2 and B1/2 types. Oppositely,

155 Impermeable Soils are only represented by D2 soils. This dataset is online accessible through the IGME Website (IGME, 2021).

\subsubsection{Land Cover Changes}

As recommended in Teuling et al. (2019), the HIstoric Land Dynamics Assessment (HILDA, v2.0) model reconstruction of historic land cover/use change (Fuchs et al., 2015) has been used. This dataset is based

160 on multiple harmonized and consistent data streams such as remote sensing, national inventories, aerial photographs, statistics, old encyclopedias, and historic maps to reconstruct historic land cover. The spatial resolution reaches $1 \mathrm{~km}^{2}$, whereas the time coverage ranges from 1900 to 2010 in decadal time steps (HILDA, 2021). The reconstruction provides information for six different land cover/use categories: forest, grassland, cropland, settlements/urban, water bodies and other. We only quantify the changes of

165 forest cover in the NENWIRES catchments. The gross land changes were studied, which compute the sum of all area gains and losses occurring within an area and period.

\subsection{Analysis Procedures}

\subsubsection{Steps to Define the Study Period}

To establish links between these multidisciplinary data sources, their time coverage should be consistent.

170 Several datasets start only from 1951 (NAOi, Precipitation, TX/TN). Henceforth, the period covers from October 1951 to September 2018. Also, in order to simplify the analysis, the large wintertime scale (December to March, DJFM) was considered. Consequently, we have considered that 1) the relation between WP and summer droughts are intensive, because recharge of reservoirs/aquifers mainly occur at wintertime (Lorenzo-Lacruz et al., 2012); and 2) WP shows the strongest and the most consistent pattern 175 of significant decline in the IP (De Luis et al., 2010, Halifa-Marín et al., 2021). In fact, we confirmed that Winter Water Inflows (WWI) explain more than 50\% of annual water inflows (Fig. 2). 


\section{Mean Annual Hydrograph of NENWIRES Series}
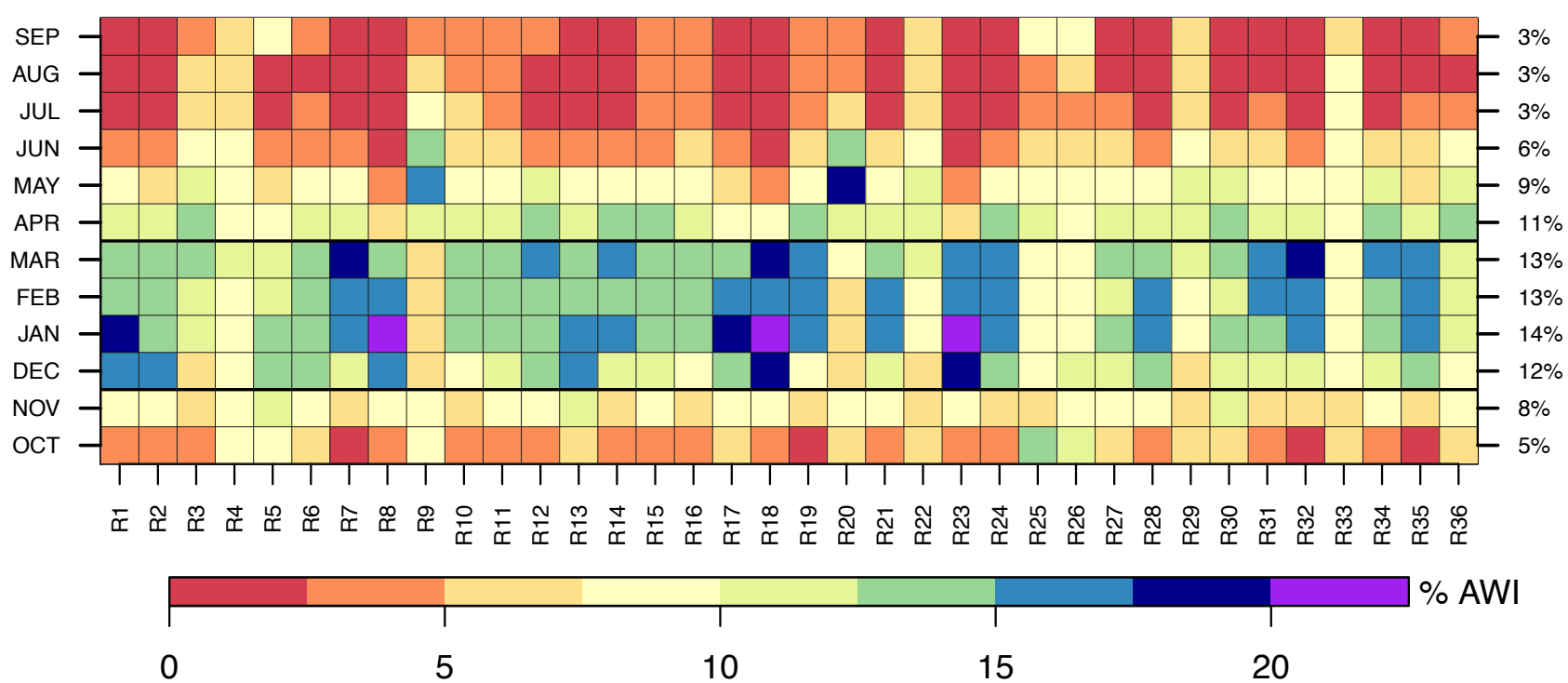

Figure 2. Hydrograph of NENWIRES dataset. It represents the monthly water inflows (MWI) to the annual water inflows (AWI) from 1952 to 2018. The total average of MWI is showed in the right axis.

\subsubsection{Pre-processing data}

Processing of NetCDF files for climate data was conducted with CDO software (Schulzweida, 2019). For converting from daily to seasonal scale (DJFM), the seassum/seasmean CDO functions were used. After having calculated the WP and winter maximum and minimum temperatures (WTX/WTN), we compute its spatial average within the target watersheds. This procedure was implemented in RCRAN language, loading the NetCDF files with the brick function (Hijmans, 2021). In addition, we read the catchments polygons (ESRI shapefile) with the readOGR function (Bivand, 2021). Then we cropped the gridded climate data within the boundaries of catchments using the mask function, and consecutively we estimated the spatial average of timesteps with the cellStats function (Hijmans, 2021). On the other hand, seasonal accumulation/average of record series was also developed in RCRAN. We referred to WWI and NAOi series from their respectively monthly data. 


\subsubsection{Statistical analysis of hydroclimate variables}

Statistical procedures were conducted in RCRAN language. First, the trend of WWI throughout the study period was obtained. This trend analysis was conducted using the Sen's slope test with sens.slope function (Pohlert et al., 2018). To allow a proportional discussion of trend analysis, slope estimates were 195 standardized (ZSS) as follows (Eq. 1):

$Z S S_{W W I}=\frac{S S_{W W I}}{\bar{X}_{W W I}}$,

where standardized Sen's slope (ZSS) is the coefficient between Sen's Slope estimate (SS) and the mean WWI for study catchments. Their statistical significance at $\alpha=.05$ has been tested. Henceforth, the same statistical significance was always tested in this contribution. Once the trend estimates were computed,

200 the potential propagation of WP abrupt change to WWI since the 1980s was quantified. For that purpose, Pettitt's Homogeneity test was used according to pettitt.test function (Pohlert, 2018).

Then, the Relative Change (RC) after the change point detected on WWI/WP was also quantified. The $\mathrm{RC}$ was calculated as follows (Eq. 2):

$205 R C=\frac{\overline{M S_{P 2}}-\overline{M S_{P 1}}}{\overline{M S_{P 1}}}$,

where the RC is estimated by subtracting the average (horizontal bars) of WWI/WP during the first period $\left(\mathrm{MS}_{\mathrm{P} 1}\right)$ to its average during the last period $\left(\mathrm{MS}_{\mathrm{P} 2}\right)$, standardizing with the early mean $\left(\mathrm{MS}_{\mathrm{P} 1}\right)$.

The significant change point detected was evaluated with the non-parametric Mann-Whitney U test 210 through the wilcox_test function (Hothorn et al., 2019). To assess the change of forest cover, HILDA provides interdecadal estimates of forest area. Then, one value per decade is available from 1950 to 2010 (7 time-steps). We thus computed the average of their interdecadal RC as (Eq. 3):

$\overline{R C}=\frac{\sum_{i=1}^{n-1} D R C_{i}}{n-1} ; D R C_{i}=\frac{D C_{i+1}-D C_{i}}{D C_{i}}$,

where the decadal cover (DC) represents the forest area in each time-step, and the mean $\mathrm{RC}(\overline{R C})$ is 215 estimated by the average of interdecadal changes (DRC). 
In addition, the correlation between hydroclimate variables was estimated. To this end, the cor.test function was used under Pearson's method (R Core Team, 2021). This function automatically provides the p-value associated to the correlation coefficients. Previously, the series were detrended using the detrend function (Borchers, 2019).

Finally, we aimed to understand whether the hydrological response changed during most humid winters. This approach is used to confirm a different hydrological response during extreme humid winters. We thus quantified the deviation between extreme percentiles of WWI/WP. So, the QQ-Deviation test (QQD) 225 was calculated as (Eq. 4):

$Q Q D=\overline{\mathrm{P}_{90}\left(Z_{W W I}\right)}-\overline{\mathrm{P}_{90}\left(Z_{W P}\right)}$,

where Quantile-Quantile Deviation (QQD) is the difference between standardized WWI/WP anomalies averaged (horizontal bars) to the points over $90^{\text {th }}$ percentile $\left(Z_{\mathrm{WWI}} / \mathrm{Z}_{\mathrm{WP}}\right)$. In the end, the analysis of meteorological droughts required the SPEI quantification, which need the ETP estimation. SPEI

230 (Hargreaves ETP) was computed with the spei (hargreaves) function (Berguería \& Vicente-Serrano, 2017). To estimate the change of preceding drought conditions, we calculated the number of winters with a mean SPEI12 lower than -0.5 (Persistent Moderate Drought conditions) and lower than -1.5 (Persistent Severe Drought conditions), before/after 1979.

\section{Results and Discussion}

\section{3.1 Variability of Near-Natural Iberian Hydrological Resources}

The results shown in Fig. 3a indicate that the mean WWI ranged from 5 to $824 \mathrm{hm}^{3}$ over the target area. Larger records were observed over the western/central sector (400-800 hm $3 / \mathrm{yr}$ ), and northern/southern areas (250-400 hm³/yr). The lower WWI were registered in the eastern/southern coast (less than $250 \mathrm{hm}^{3}$ ). Meanwhile, the trends ranged from -1.8 to $0.1 \% / y r$ (Fig. 3b). 97\% of WWI series have decreased in the 240 study period. These WWI reductions were significant in most of catchments (55\%), mainly over central and eastern sectors. Also, significant reductions frequently occurred in the most humid basins. WWI only 
increased in one basin, but not significantly. The results thus depict significant reductions in the headwater of the Tagus, Ebro, Douro, Segura, Jucar, and Mino basins.
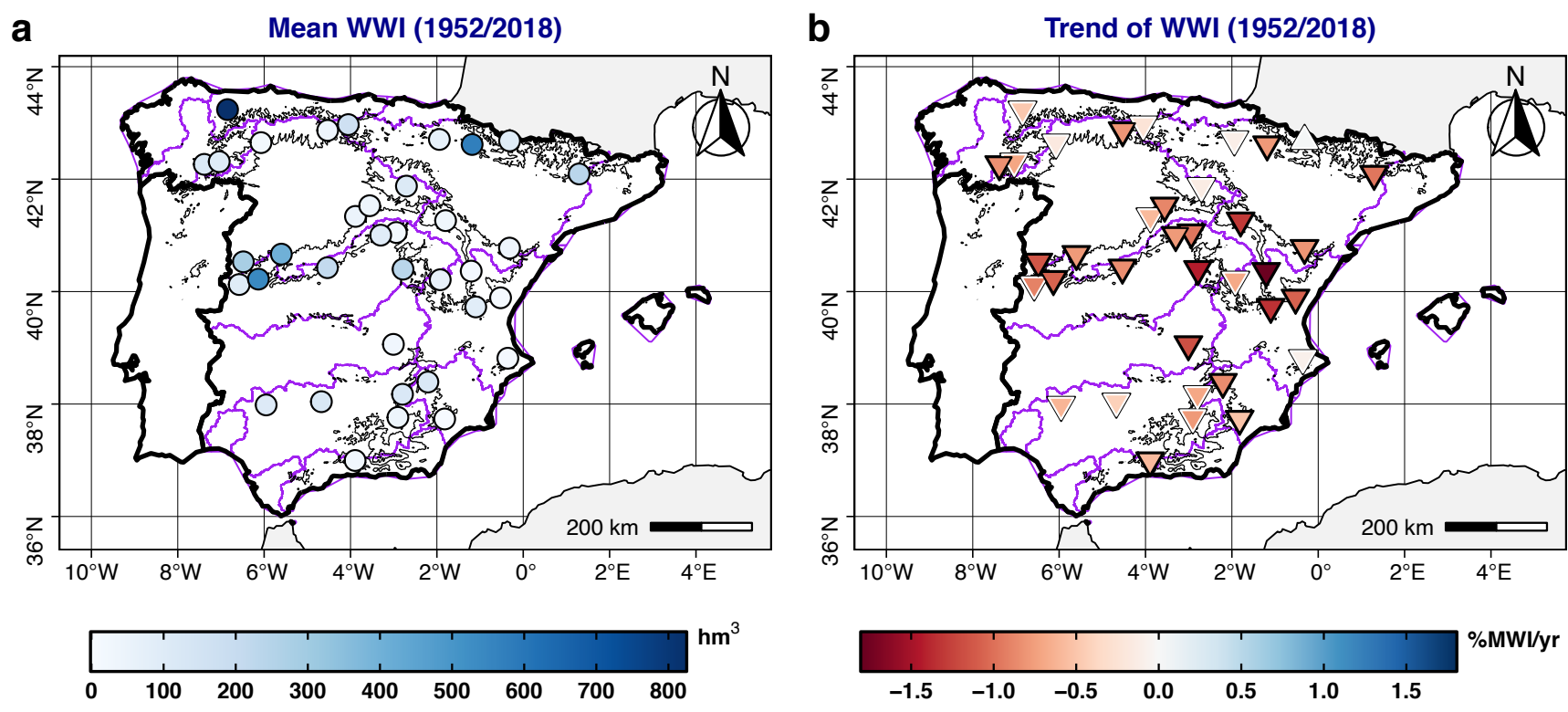

245 Figure 3. (a) Mean Wintertime Water Inflows (WWI), and (b) its Standardized Sen's slope trend estimates computed after Eq. 1. For the trends, symbols represent positive trend (filled triangle/point-up) and negative trend (filled triangle/point-down). Significant estimates are indicated with a black outline.

\subsection{Evidence of Climate-Driven Changes on Wintertime Water Inflows}

250 A lead role of WP to modulate the streamflow was already described in Trigo et al. (2004) and LorenzoLacruz et al. (2012). However, recent studies have noticed a sudden decline of WP in the Tagus, Jucar, and Guadalquivir basins since the early 1980s (Guerreiro et al., 2014, Gómez-Martínez et al., 2018, Halifa-Marín et al., 2021). To analyse the potential propagation of this WP abrupt decline into the WWI variability, the significant break point in the total average of WP/WWI was calculated (Fig. 4). Both

255 variables had a significant abrupt shift since 1979 and are highly correlated (0.87). For WP, mean reductions reached $-19 \%$ after the break point, with WWI declining by $-33 \%$. Therefore, WWI decreased more than WP. 


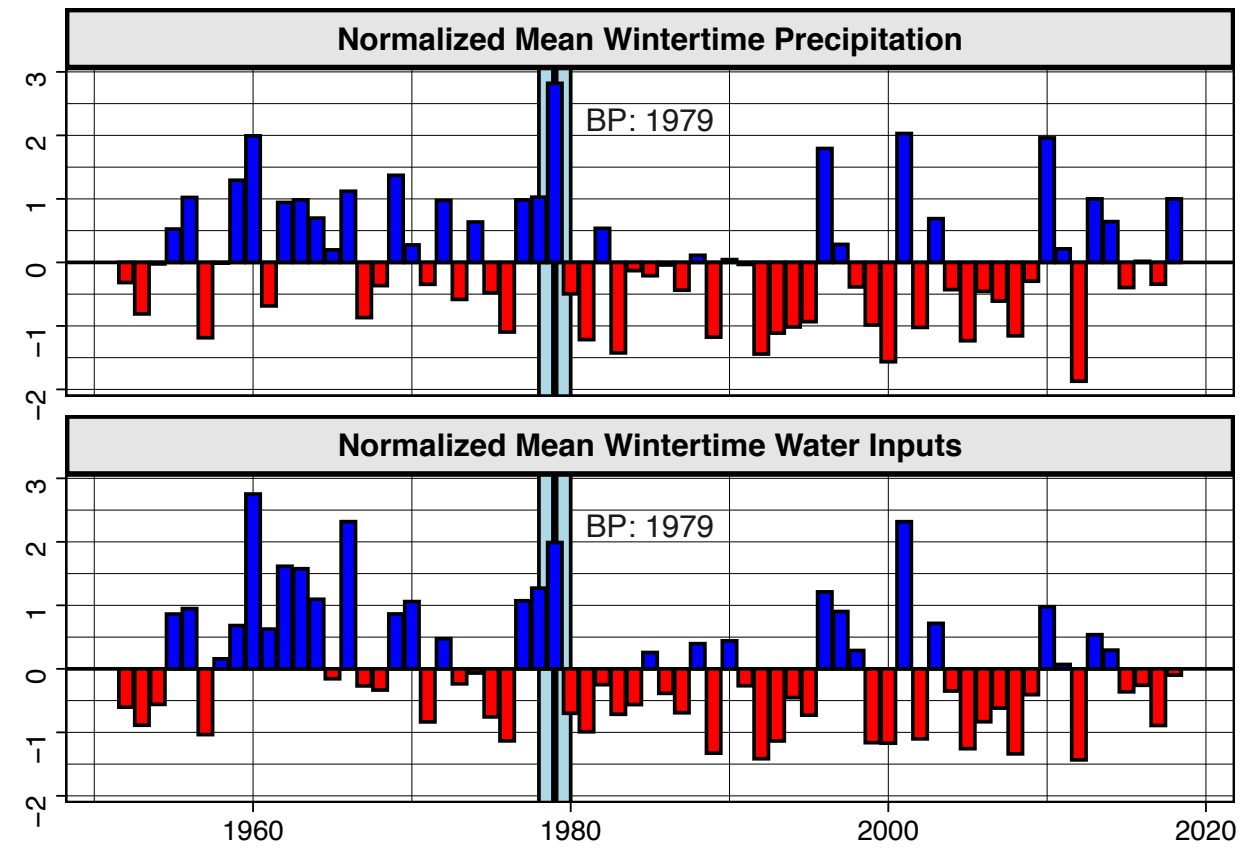

Figure 4. Standardized series from Mean Wintertime Precipitation (upper) and Mean Wintertime Water

Inflows (lower) in the NENWIRES dataset during the period 1952/2018. Bars represent negative (red) and positive (blue) values. Vertical blue/black line represents the most probable change detected (break point, BP).

In the case of catchments (Fig. 5), 75\% of precipitation series present a break point, which is significantly detected in 1979 for 58\% of target basins from southwestern to northern/eastern IP. This pattern is consistent with the results of Halifa-Marín et al. (2021) for southern IP. However, the break point differs for eastern/northern IP. Moreover, the break point in 1979 was not consistently detected in the WWI series (only 36\% of catchments), but from 1978 (5\%) to 1980 (14\%). Hence, a break point was found in $72 \%$ of WWI series between 1978 and 1980, although only 55\% of detections were significant. The spatial 270 pattern had the same features that the detection of break for WP. WP changed in 1979, and WWI also varied between 1978 and 1980. Our results agree with those of Gómez-Martínez et al. (2018), who noticed the concomitant WWI/WP abrupt changes in the headwater of Jucar basin since 1980s. 
a

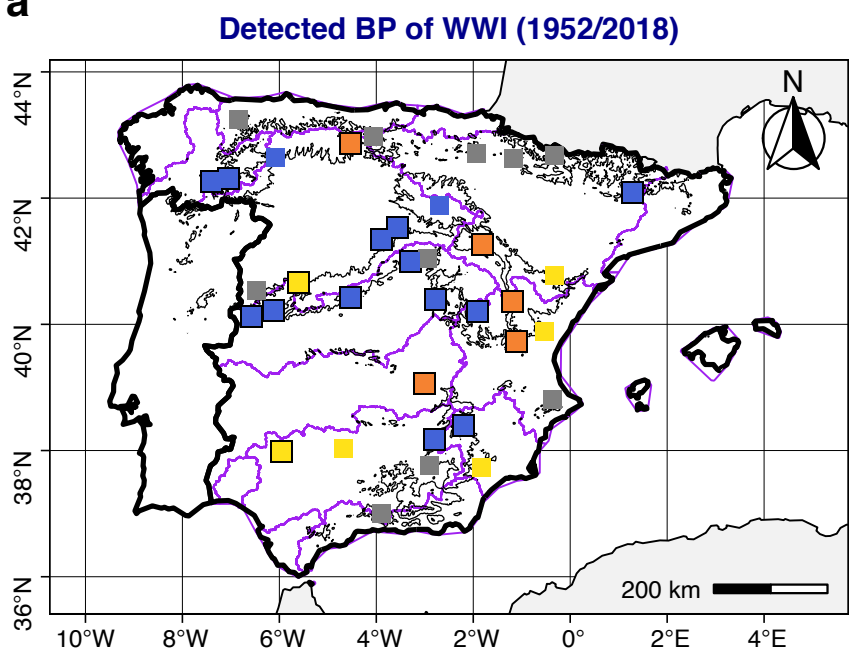

b

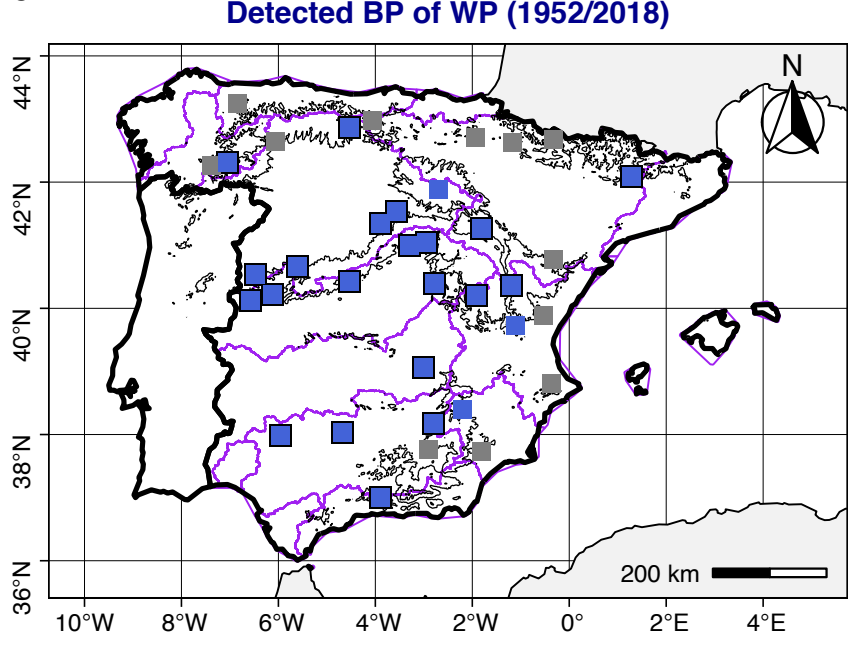

BP $1978 \square 1979 \square 1980$

Figure 5. (a) The break point (BP) detected for WP series; and (b) similarly for WWI series. Grey squares

275 represent a BP not detected between 1978 and 1980. Larger squares (framed into black contours) represent the significant BP.

After characterizing the precipitation-driven shift of WWI, changes of WP/WWI were assessed (Fig. 6). The relative change of WP ranged from $-40 \%$ to $10 \% .61 \%$ of catchments registered a significant relative change of WP. WP losses generally appeared from 1980. The significant relative change was observed in the central areas and western/southern IP. Those negative relative changes also occurred where the breaking point was not detected (i.e., northern IP). Conversely, a positive relative change of WP was estimated in the eastern IP. For WWI, all catchments registered losses. The relative change of WWI ranged from $-60 \%$ to $-3 \%$. Major WWI decreases were observed in the headwater of Tagus, Jucar, and

285 Segura basins. These territories store an important part of water resources in the IP, but these WWI losses generally are higher than reductions of WP. That is, WWI decreased where the relative changes of WP increased. This incoherent pattern suggests a poor relationship between WP and WWI in several NENWIRES basins. 
a

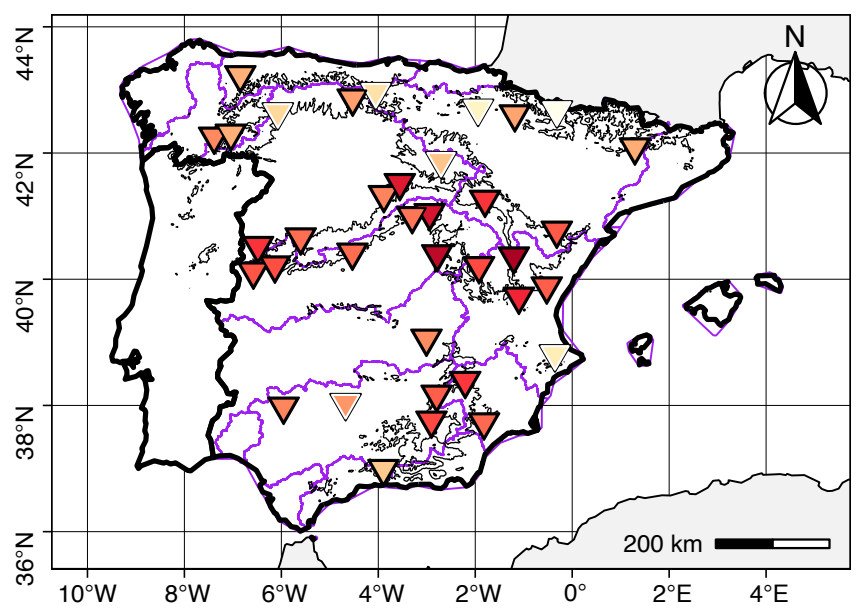

b

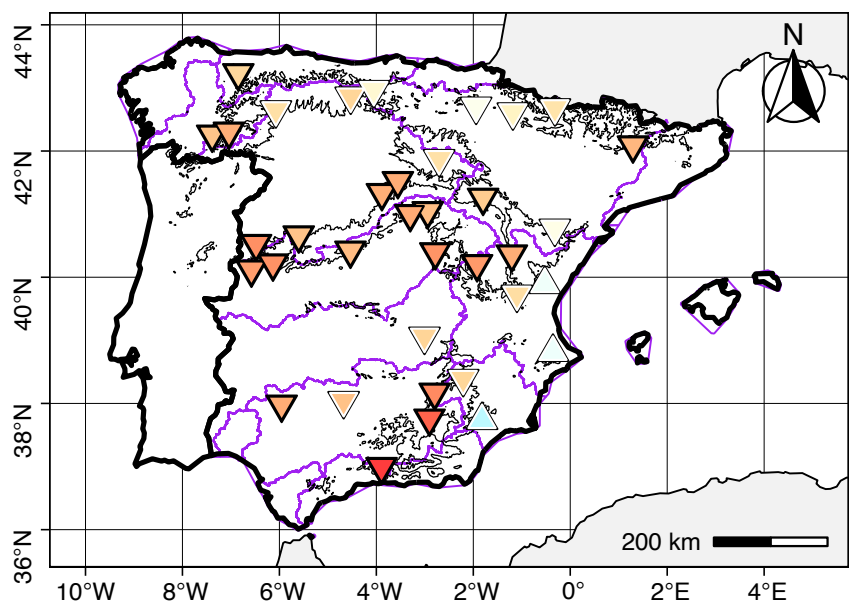

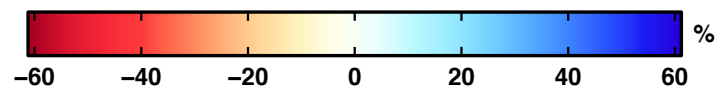

Figure 6. (a) The Relative Change (RC) of WP since 1979; and (b) Similarly for WWI. The RC is computed as Eq. 2. Symbols represent positive RC (filled triangle point-up) and negative RC (filled triangle point down), being marked with a black outline the significant estimates.

295 At this point, results are not conclusive about the incoherent WP/WWI changes through the study period: 1) an abrupt shift of WP was observed, causing the decline of WWI, but climate dynamics promoting the WP change were not clarified; 2) at the same time, an increase of WP was found, but WWI decreased in several catchments; and 3) larger losses were found in WWI than in WP.

\subsection{Wintertime Iberian Meteorological Droughts caused by NAO+}

The aforementioned results have demonstrated that WP suddenly decreased since early 1980s. The scientific literature had already warned about the WP abrupt decreases in some IHB, which were linked to the large-scale influence (Guerreiro et al., 2014, Gómez-Martínez et al., 2018, Halifa-Marín et al., 2021). They noticed an abrupt shift of wintertime NAOi since late1970s/early 1980s. In this sense, a significant break point for wintertime NAOi since 1980 was detected here (Fig. 7a). The average NAOi 
changed from $-0.35(1952 / 1979)$ to $0.38(1980 / 2018)$. This simplification of large-scale atmospheric patterns usefully helps to understand the principal moisture sources reaching the IP (e.g., Trigo et al., 2004). The negative phases of the NAO index (NAOi-) are related to low systems affecting the IP, promoting moisture fluxes from the SW (Fig. 7b). NAOi+ represents the opposite synoptic pattern. We

310 obtained an identical synoptic pattern between NAO-(NAO+) and the climatology of mean sea level pressure in the before(after) the shift of 1980. A higher frequency of NAO+(NAO-) thus coincided with WP/WWI declining(rise) in the IP. Conversely, the increase of the frequency of NAO+ was associated to the streamflow gains in northern Europe since 1980s (Stahl et al., 2010, Hannaford et al., 2013, Teuling et al., 2019). This opposite pattern between streamflow gains(losses) between northern(southern) Europe

315 has already been pointed out by the scientific literature (Hannaford et al., 2013). These latitudinal opposite trends of European streamflow are probably linked to NAOi.

a

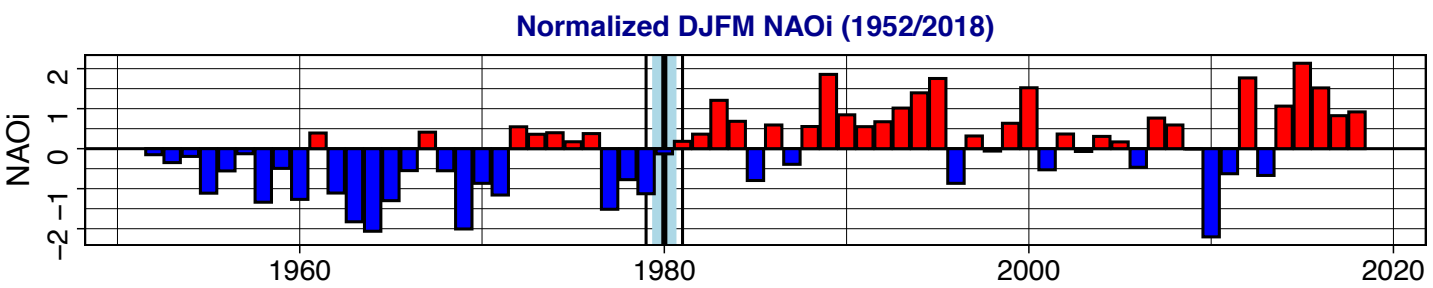

b

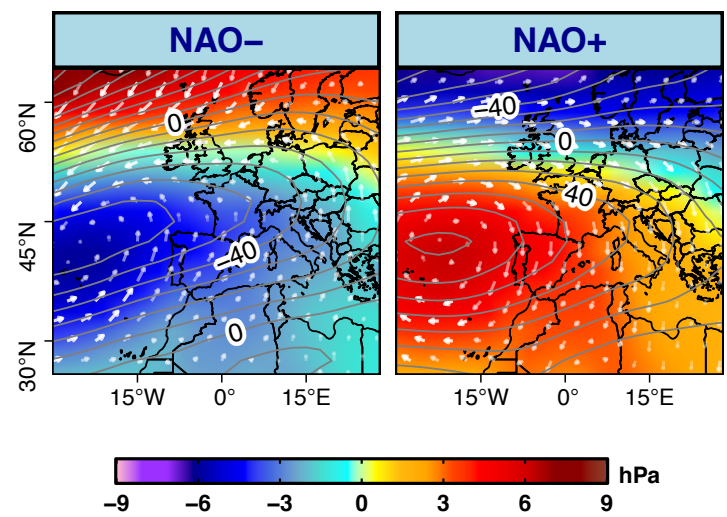

C

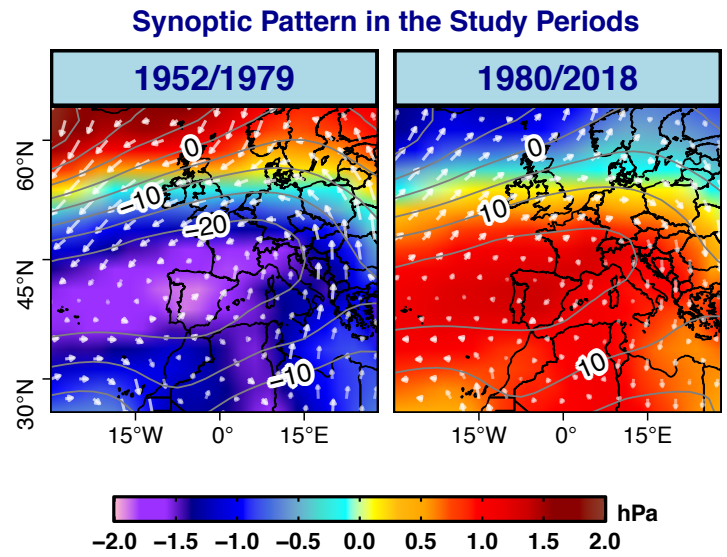

Figure 7. (a) Standardized wintertime NAOi (DJFM) and its detected change from 1952 to 2018; (b) the synoptic pattern (sea level pressure and wind speed/direction anomalies) based on NAO+/NAO- phases; 
and (c) similarly for the study periods 1952/1979 and 1980/2018. Contours represent the anomaly of geopotential height at $500 \mathrm{mb}$.

Therefore, WP/WWI highly correlated with the NAOi in the target catchments (Fig. 8). The correlation

WP/NAOi ranged from - 0.7 to -0.1 . Negative correlation between WP and NAOi were observed. These inverse associations were mostly significant except in the case of eastern/northern IP. The correlation is higher where the break point of WP/WWI occurred in 1978/1980. Focusing on WWI/NAOi links, a similar spatial pattern (less intense) although non-significant positive correlations were observed in the eastern IP. In this case, correlation coefficients ranged from -0.6 to 0.2 . However, the relationship between

330 NAOi/WP was more intense than NAOi/WWI. The drastic declining of WWI might be preliminary attributed to NAOi. The results presented here allow to highlight the links between the increase of NAOi+ and the decline of WP over southern Europe. Therefore, WWI losses were modulated by NAOi in most of the IP.

a

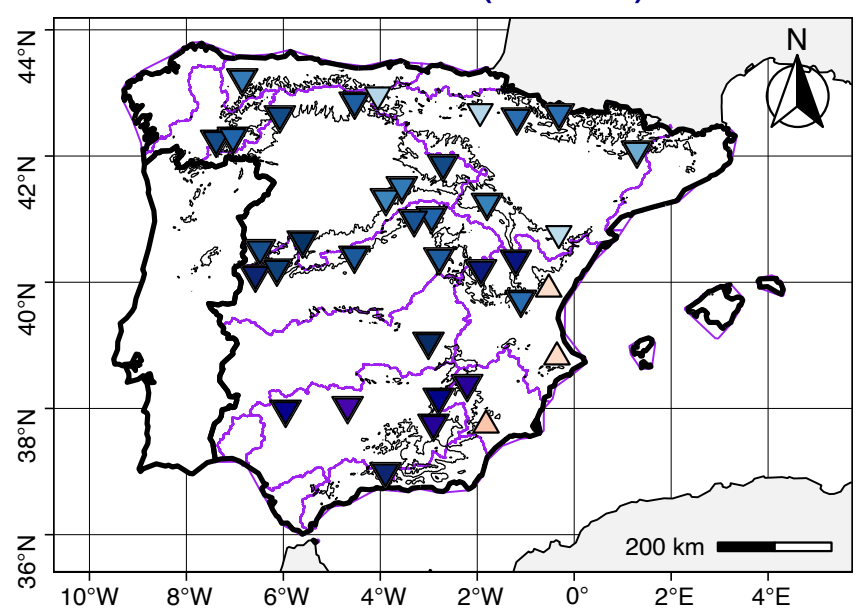

b

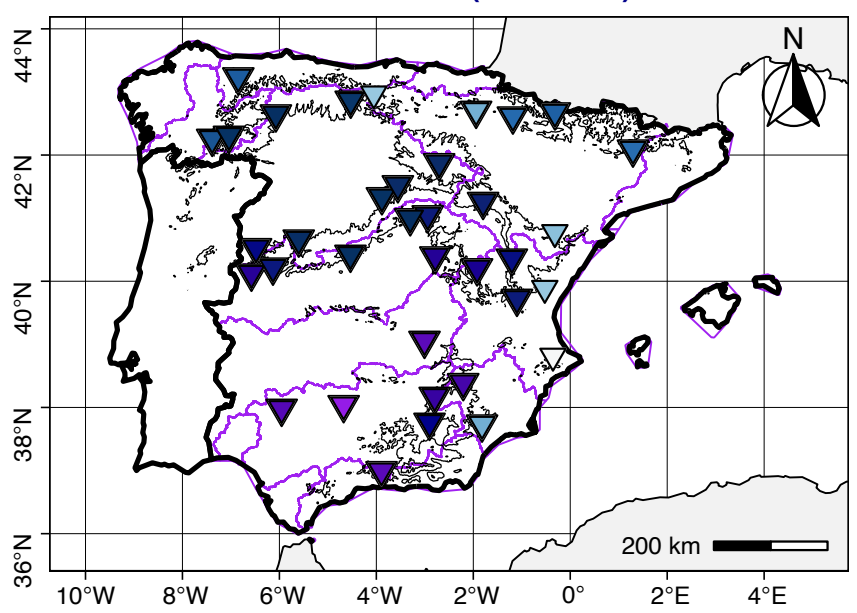

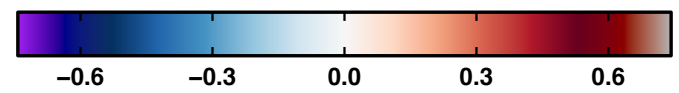

Figure 8. The wintertime correlation between NAOi and (a) precipitation; and (b) water inflows. Symbols represent positive correlation (filled triangle point-up) and negative correlation (filled triangle point down), being marked with a black outline the significant estimates. 
340 Whereas uncertainties about the drivers which have promoted the NAOi shift persist (Luo \& Gong, 2006, Wang et al., 2014), the results comprehensively confirm its influence into the behaviour of Iberian water resources. If $\mathrm{NAO}+$ enhancement persists, the availability of fresh water could strongly be affected in the Mediterranean. However, the results presented are limited in order to disentangle the noticeable decrease of WWI in eastern/northern IP. Henceforth, other factors should explain the lack of understanding about 345 the Iberian WWI declining.

\subsection{The Frequency of Meteorological Droughts}

To estimate the previous conditions of soil moisture and the water reserve of aquifers each winter, the changes of SPEI12 (Fig. 9) have been quantified. The results depict an increase of Persistent Moderate Droughts (PMD) conditions preceding the winter season from 1980. All catchments have recorded the increase of PMD events. The increase of PMD frequency ranged from 0.5 to 7.5 events/decade. Likewise, the rise of PMD was higher over central/southern IP. Also, the results prove the increases of Persistent Severe Droughts (PSD) events, ranging from -0.5 to 2.1 events/decade. The higher increase of PDS appeared on northern/western IP. These estimates highlight the positive variations of meteorological

355 droughts conditions, which can affect to the hydrological response in the target catchments. Large increases of MMD events often occur where WP is limited to explain the reductions of WWI. The links between rising temperatures with increasing meteorological droughts has been unrevealed for the IP (Vicente-Serrano et al., 2014). The results here suggest that the increased temperature and ETP have been encouraged by the NAO shift, given that winter maximum temperatures ignificantly correlated with WP $360(-0.45)$. 

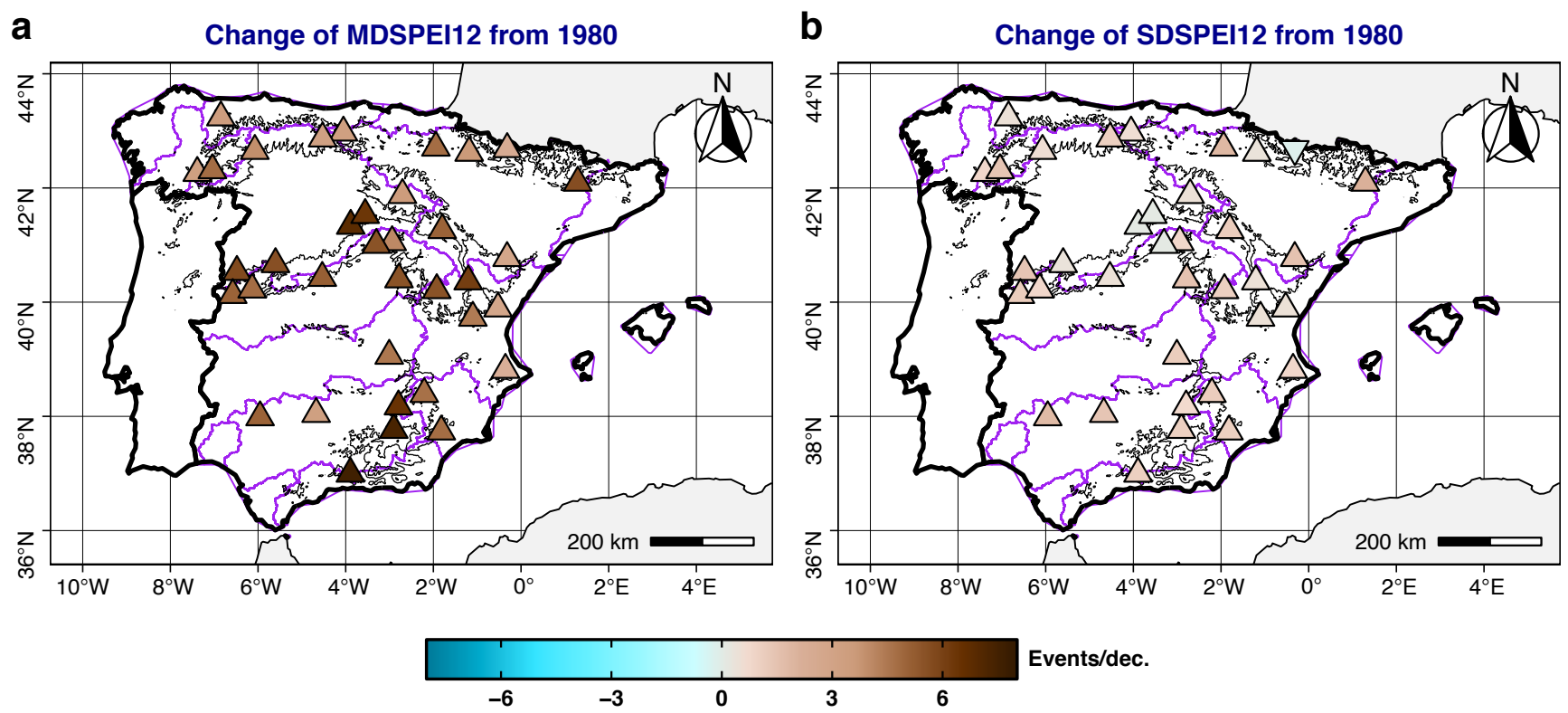

Figure 9. (a) Absolute change of wintertime moderate droughts conditions (MDSPEI12) between 1980/2018 and 1952/1979; and (b) similarly for severe droughts conditions (SDSPEI12). Symbols represent a positive change (filled triangle, point-up) and negative change (filled triangle, point-down).

\subsection{Permeable Soils Holding the Time-lag of Hydrological Response}

Two types of target catchments were found depending on its permeability characteristics: 1) those where permeable soils prevailing, which were mostly found over the central/eastern IP; and 2) those where impermeable soils prevailed (western IP). The permeable soils exceeded $80 \%$ in southeastern catchments (Fig. 10). In contrast, impermeable soils reached $100 \%$ in the western IP. 

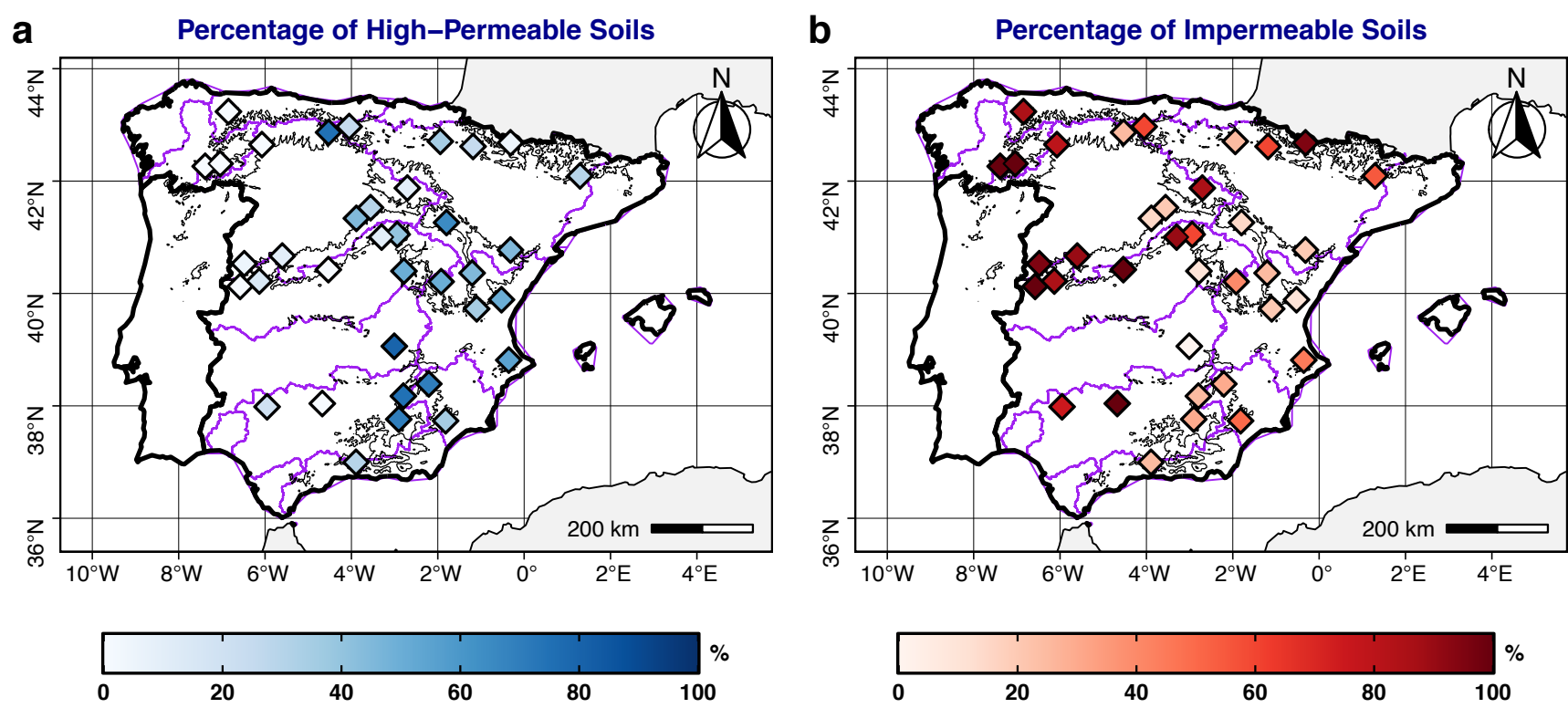

Figure 10. Percentage (\%) of (a) high-permeable soils and (b) impermeable soils.

On the other hand, the correlation between WP and WWI (Fig. 11a) was checked. Correlation coefficients

375 ranged from 0.3 (southeastern IP) to 0.9 (northwestern IP). WP and WWI are highly correlated (0.8-0.9) where impermeable soils prevail. This result is physically coherent because the run-off response must be instantaneous. Conversely, some permeable watersheds showed a poor correlation between WP/WWI. In brief, correlation coefficients have shown a gradual loss from western (impermeable) to eastern IP (permeable).

After WP/WWI correlation was estimated, the QQ-Deviation (QQD) (Fig. 11b) was quantified. In several catchments, the magnitude of WWI anomalies was higher than WP records during extreme humid winters $\left(90^{\text {th }}\right.$ percentile). The role of permeable soils to generate higher WWI was mostly proved. Whereas QQD showed negative estimates over the northern/western IP (impermeable soils), positive estimates have been

385 found in the high-permeable catchments (eastern/southern). These results can be explained as follows: 1) porous watershed can infiltrate a larger volume of water; 2) Iberian extreme events of WP are characterized by the persistence of wet days through several weeks; 3) which allow the water accumulation into aquifers; 4) generating an underground baseline flow joint to the surface run-off. 
Therefore, the response between WP and WWI anomalies is higher in relation to dry winters. The timelag effect probably depends on the hydrological response/water yield and the capacity of watersheds to store water in their aquifers.
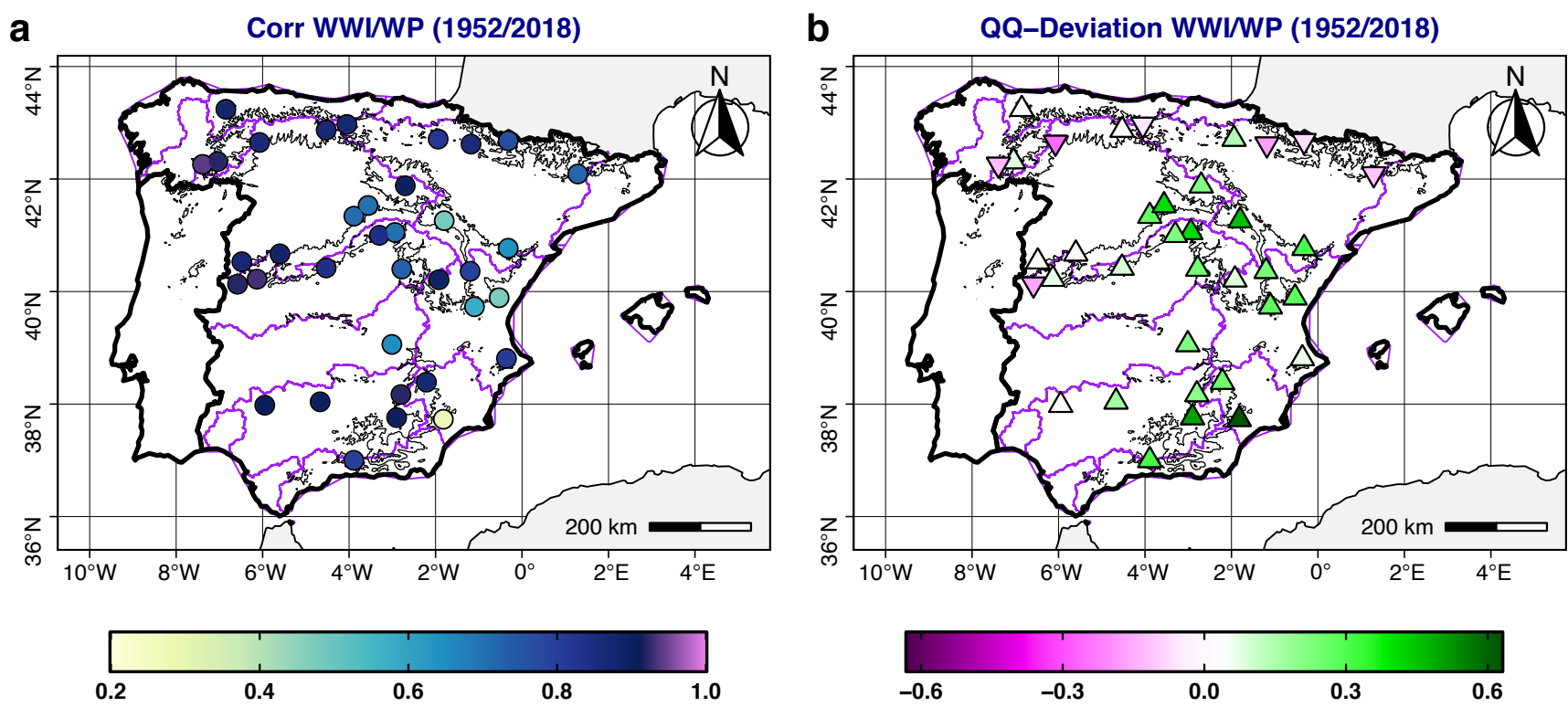

Figure 11. (a) The wintertime correlation between water inflows and precipitation; and (b) the QQ-

deviation in the most humid monthly records (computed after Eq. 4). All correlation coefficients were significant. For QQ-deviation, symbols represent positive deviation (filled triangle, point-up) and negative deviation (filled triangle, point-down).

\subsection{Land Greening-up Promoting the Water Stress}

400 After having described most of the physical drivers, the role of land cover into the NENWIRES hydrological response was further explored. The results widely registered the extension of forest cover from 1950 to 2010 (Fig. 12). The relative changes of forest cover ranged from $-60 \%$ to $90 \%$ until 2010. Those forest extensions grew thanks to the cropland abandonment and afforestation works. From 1950 to 2010 , forest areas extended in $67 \%$ of the catchments. Forest areas mainly did not extent in the 
northern/southeastern IP. Also, the greening-up was limited where forest already exceeded $80 \%$ of watershed area in 1950 .
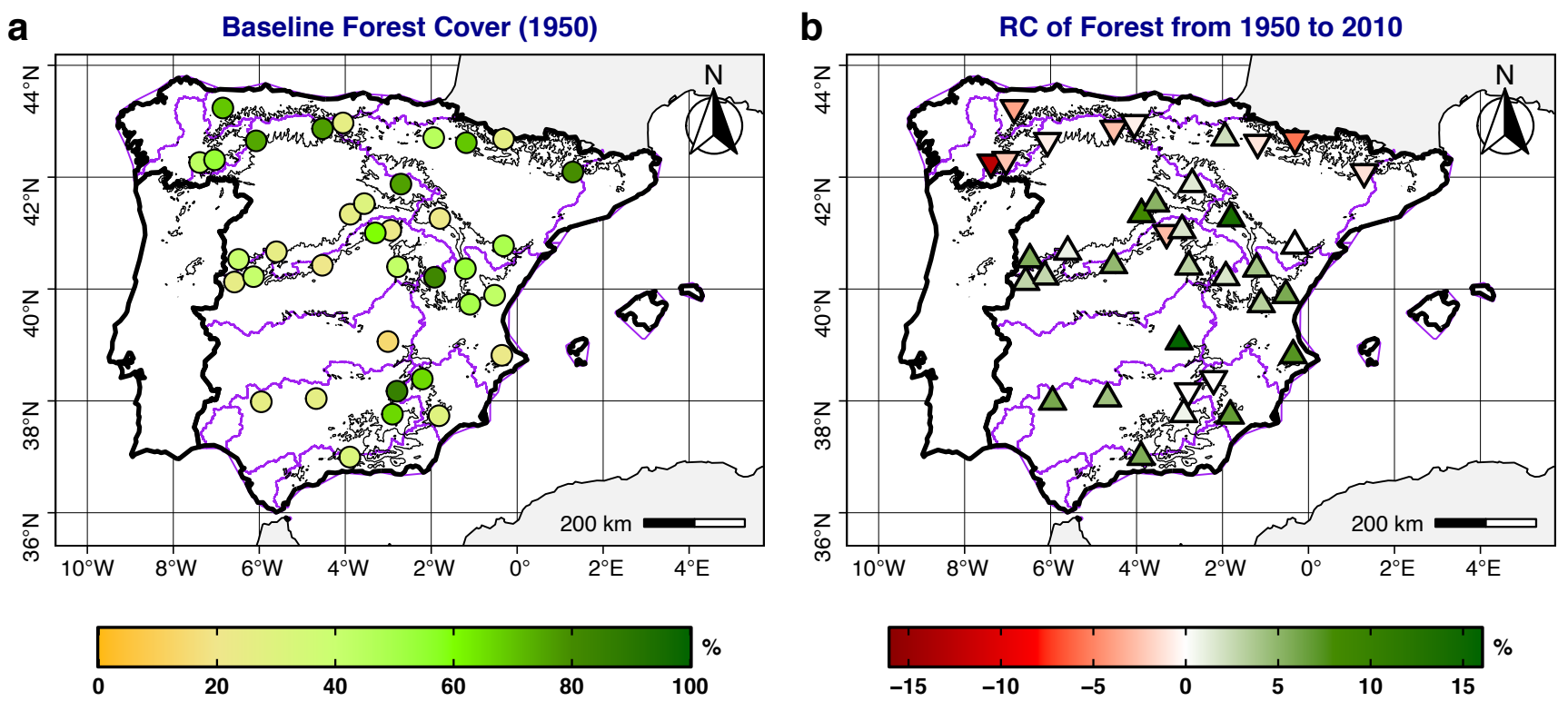

Figure 12. (a) Percentage of forest cover in 1950; and (b) its mean relative change (RC) from 1950 to

4102010 computed after Eq. 3. In case of the RC, symbols represent positive RC (filled triangle, point-up) and negative RC (filled triangle, point-down).

Finally, the results indicate that the lower mean WP, the larger forest extension through the study period. In this sense, the significant role of land greening-up to decrease the WWI in semiarid catchments was 415 proved. On the other hand, the pattern of WWI changes differed. The relative change of WWI ranged from $-65 \%$ to $17 \%$ under the semiarid conditions; from $-45 \%$ to $-2 \%$ under transitional conditions; and from $-28 \%$ to $-19 \%$ under humid conditions (Fig. 13). The relative changes of WI were higher than the decline of WP over semiarid catchments. A high correlation between the total relative changes of forest area from 1950 to 2010 and mean WP was found (-0.68). The total relative changes of forest area were 420 higher over semiarid basins. Also, a larger decrease of relative changes of WWI was quantified related to those of WP, precisely over semiarid catchments. The results clearly depict how the vegetation control of WWI changes. The magnitude of the relative changes for WP/WWI is similar in the transitional and 
humid catchments. However, semiarid environment, where forest widely extended, registered a higher relative change of WWI. Furthermore, the NAOi cannot be related to the hydroclimate variability in these watersheds. Therefore, the links with NAO are not robust in the semiarid catchments, whereas a modulation of WWI reductions due to NAOi was observed in most of target basins.

\section{Links with Mean WP of Catchments}

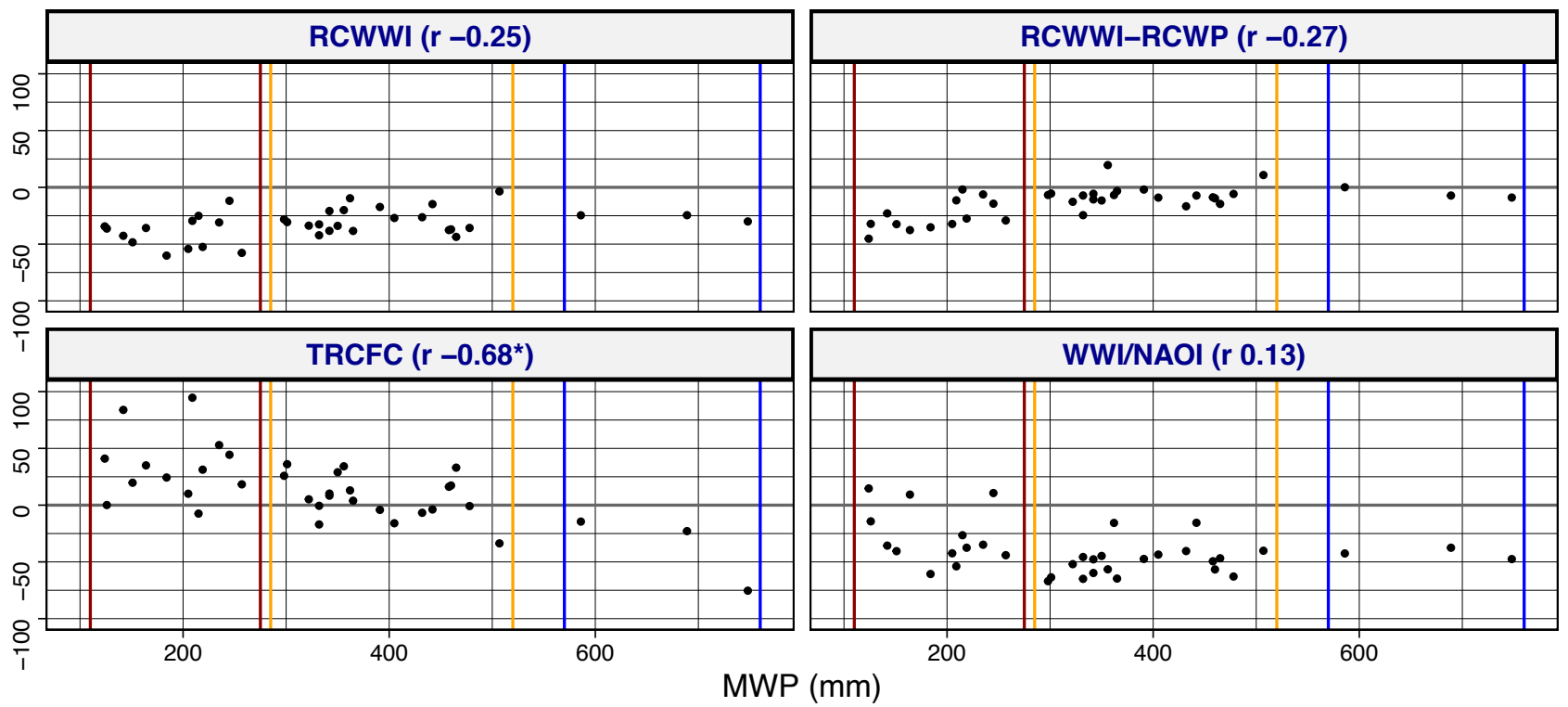

Figure 13. The RC of WWI (bottom right), the RC of WWI minus RC of WP (top left), the RC of forest area from 1950 to 1980 (top right), and NAOi (bottom left) were related to the MWP of NENWIRES catchments. Three levels are highlighted: semiarid basins (red) from 110 to $275 \mathrm{~mm} /$ winter; transitional basins (orange) from 285 to $520 \mathrm{~mm} / \mathrm{yr}$; and humid catchment (blue) from 570 to $760 \mathrm{~mm} /$ winter.

Whereas Gudmundsson et al. (2021) linked the strongest declining of water resources in the Mediterranean to anthropogenic global warming, Vicente-Serrano et al. (2019) attributed the lead role of human-induced impacts to the decrease of streamflow in southern Europe. According to these latter authors, the extension of irrigated areas, agricultural intensification, and natural revegetation of marginal lands of mountain areas were the main drivers of decreases in streamflow, specially over the southern IP. Peña-Angulo et al. (2021) have also demonstrated the intensification of meteorological droughts due to the vegetation extension in the IP. A similar conclusion was presented for the Mediterranean basin 
(García-Ruiz et al., 2011) and Europe (Teuling et al., 2019). The NENWIRES dataset were created to shed light on the observed variability of near-natural Iberian hydrological resources during the last decades. Our results agree to other near-natural hydrological studies which analysed several basins in Europe (Stahl et al., 2010, Hannaford et al., 2013). These contributions found decreases of streamflow in

445 southern Europe. We have quantified the observed changes of WWI, while several multidisciplinary drivers were attributed. Thus, we follow the Massei et al. (2020) recommendations to current hydrological studies.

The results of our multivariate approach agree with those of Teuling et al. (2019), which also studied the role of several drivers in the European streamflow variability. Their conclusions for the IP warn about the decrease of streamflow promoted by climate/anthropogenic drivers. This contribution, based on nearnatural basins, presents a similar conclusion. One the one hand, the WWI declining since the late/early 1970/1980s was highlighted here. These climate-driven reductions were promoted by the increase of $\mathrm{NAO}+$ persistence/events. Therefore, WP events coming from the Atlantic Ocean declined in the IP 455 between December and March. The results presented here thus confirm the propagation effect from the noticeable WP abrupt change to the WWI behaviour. This connection has been already described by Gómez-Martínez et al. (2018) in the Jucar basin. Our results for the same basin also warned about the WP/WWI decline promoted by NAOi+. If NAOi+ phases also prevailing during the next years/decades, the freshwater scarcity could increase in the Iberian territories.

This work also highlights other drivers contributing to the WWI declining. The results herein proved the increase of meteorological droughts preceding the winter season (which represents the wet season for most of the IP). The role of permeability in the hydrological response was also estimated; basically, welldrained soils allow the recharge of aquifers, inducing a time-lag effect on WWI series. This result agrees 465 with Lorenzo-Lacruz et al. (2013). Likewise, it contributes to increase wintertime floods in the most humid winters. Finally, the lead role of land greening-up was shown in semiarid environments of the IP. The abovementioned area is framed in the Mediterranean/eastern sector of the IP. These areas were a priority objective for afforestation during the $20^{\text {th }}$ Century (García-Ruíz et al., 2011, Vicente-Serrano et 
al., 2019, Peña-Angulo et al., 2021). The eastern IP is often damaged by extreme rainfall events which promote the erosion of soils. Thus, afforestation works were mainly designed for the erosion control. Where WP is low (150-250 mm), the human-induced afforestation determined the WWI decline. Although these afforestation works have been useful to control the erosion processes and run-off, they could strengthen the warmer climate impacts to the water cycle in the Mediterranean. As confirmed by Vicente-Serrano et al. (2014), the increased ETP probably explain the declining WWI where the forest area extended. Nonetheless, our final remarks conclude that the confluence of all factors explains the WI reductions in the target catchments.

\section{Conclusions}

This work has assessed the long-term variability of Iberian water resources based on a multivariate-driven approach. For that purpose, we have used the novel dataset of Near Natural Water Inflows to Reservoirs of Spain (NENWIRES) based on 36 study catchments. A multivariate approach was used to understand WWI changes observed through 1952/2018. Summarizing, the main findings of this contribution are listed below:

- WP decline has shown a lower magnitude than overall WWI losses.

- All headwater of IHB were affected by the WWI reductions.

- The WP declining was associated to NAOi+ enhancement from the early 1980s.

- However, Iberian semiarid catchments were not mainly influenced by NAOi variability.

- The intensification of WWI decline was linked to the land greening-up.

- The confluence of both drivers (climate, human-induced) exacerbated droughts events.

490 - Also, the role of other secondary drivers was highlighted (permeability time-lag modulation).

- The WWI specially decreased in the headwater of Jucar, Tagus, and Segura basins. 
495 Our findings encourage the need to develop future works which enhance the knowledge about NAOi+ behaviour under a warmer climate; and recommend the high-resolution modelling of the influence of land cover changes to the hydrological response in semiarid catchments. Henceforth, we hope that our work can contribute to the mitigation of warmer climate impacts on water cycle/planning in the MED/IP or other global semiarid environments.

Data availability. All data sets used in the current study are publicly available from the indicated references or sources. Also, we will be pleased to send the full dataset under request.

Author contributions. A.H-M conceived the original idea and designed the overall study. A.H-M, E.P-S and M.T-V developed the NENWIRES dataset. A.H-M, and JP.M performed the analysis. All co-authors contributed to the interpretation of the results. A.H-M led the writing of the paper, with contributions of P.J-G.

Competing interests. The authors declare that they have no conflict of interest.

Acknowledgements. The authors acknowledge the ACEX project (CGL2017-87921-R) of the Ministerio de Economía y Competitividad/Agencia Estatal de Investigación of Spain, the ECCE project (PID2020115693RB-I00) of Ministerio de Ciencia e Innovación/Agencia Estatal de Investigación (MCIN/AEI/10.13039/501100011033/) and the European Regional Development Fund (ERDF/ FEDER

515 Una manera de hacer Europa). Also, the authors thank the reviewers for their valuable contributions and fruitful discussions. A.H-M thanks his predoctoral contract FPU18/00824 to the Ministerio de Ciencia, Innovación y Universidades of Spain. E.P-S thanks for his predoctoral contract to the ACEX project. M.L-C thanks his predoctoral contract FPU17/02166 to the Ministerio de Ciencia, Innovación y Universidades of Spain. 


\section{References}

AEMET, Precipitation/Temperature Gridded Dataset, available at: http://www.aemet.es/es/serviciosclimaticos/cambio_climat/datos_diarios?w=2, last access: 20 October 2021.

Berguería, S., Vicente-Serrano, S.M.: SPEI: Calculation of the Standardised Precipitation-

Evapotranspiration Index, $\mathrm{R}$ package version 1.7, available at: https://cran.rproject.org/web/packages/SPEI/index.html, last access: 20 October 2021.

Bivand, R.: Rgdal: Bindings for the 'Geospatial' Data Abstraction Library, R package version 3.4.13, available at: https://cran.r-project.org/web/packages/rgdal/index.html, last access: 20 October 2021.

Borchers, H.W.: Pracma: Practical Numerical Math Functions, R package version 2.2.9, available at: https://CRAN.R-project.org/package=pracma, last access: 20 October 2021.

CEDEX, Spanish Hydrological Repository, available at: https://ceh.cedex.es/anuarioaforos/demarcaciones.asp, last access: 20 October 2021.

de Luis, M., Brunetti, M., González-Hidalgo, J. C., Longares, L. A., \& Martin-Vide, J.: Changes in seasonal precipitation in the Iberian Peninsula during 1946-2005, Global and Planetary Change, 74, 27-33, doi:10.1016/j.gloplacha.2010.06.006, 2010.

Fuchs, R., Herold, M., Verburg, P. H., Clevers, J. G. P. W., and Eberle, J.: Gross Changes in Reconstructions of Historic Land Cover/Use for Europe between 1900 and 2010, Glob. Change Biol., 21, 299-313, https://doi.org/10.1111/gcb.12714, 2015.

García-Ruiz, J. M., López-Moreno, J. I., Vicente-Serrano, S. M., Lasanta-Martínez, T., \& Beguería, S.:

Mediterranean water resources in a global change scenario, Earth-Science Reviews, 105(3-4), 121 139, https://doi.org/10.1016/j.earscirev.2011.01.006, 2011.

Gómez-Martínez, G., Pérez-Martín, M. A., Estrela-Monreal, T., \& del-Amo, P.: North Atlantic Oscillation as a Cause of the Hydrological Changes in the Mediterranean (Júcar River, Spain), Water Resources Management, 32(8), 2717-2734, doi:10.1007/s11269-018-1954-0, 2018.

545 Gudmundsson, L., Boulange, J., Do, H. X., Gosling, S. N., Grillakis, M. G., Koutroulis, A. G., ... \& Zhao, F.: Globally observed trends in mean and extreme river flow attributed to climate change, Science, 371(6534), 1159-1162, 2021. 
Guerreiro, S. B., Kilsby, C. G., \& Serinaldi, F.: Analysis of time variation of rainfall in transnational basins in Iberia: Abrupt changes or trends?, International Journal of Climatology, 34, 114-133, doi:10.1002/joc.3669, 2014.

Halifa-Marín, A., Lorente-Plazas, R., Pravia-Sarabia, E., Montávez, J. P., \& Jiménez-Guerrero, P. (2021). Atlantic and Mediterranean influence promoting an abrupt change in winter precipitation over the southern Iberian Peninsula, Atmospheric Research, 253, 105485, https://doi.org/10.1016/j.atmosres.2021.105485, 2018.

555 Hannaford, J., Buys, G., Stahl, K., and Tallaksen, L. M.: The influence of decadal-scale variability on trends in long European streamflow records, Hydrol. Earth Syst. Sci., 17, 2717-2733, https://doi.org/10.5194/hess-17-2717-2013, 2013.

Hijmans, R.J.: Raster: Geographic Data Analysis and Modeling, R package version 3.4.13, available at: https://cran.r-project.org/web/packages/raster/index.html, last access: 20 October 2021.

560 HILDA, HIstoric Land Dynamics Assessment Dataset, available at: https://www.wur.nl/en/ResearchResults/Chair-groups/Environmental-Sciences/Laboratory-of-Geo-information-Science-andRemote-Sensing/Models/Hilda.htm, last access: 20 October 2021.

Hothorn, T., Winell, H., Hornik, K., van de Wiel, M.A., Zeileis, A.: Coin: Conditional Inference Procedures in a Permutation Test Framework, $\mathrm{R}$ package version 1.3-1, available at: https://CRAN.R-project.org/package=coin, last access: 20 October 2021.

IDE, Spanish Catchment Boundaries Dataset, available at: https://www.miteco.gob.es/es/cartografia-ysig/ide/descargas/agua/cuencas-y-subcuencas.aspx, last access: 20 October 2021.

IGME, Mid-Resolution Permeability of Soils Dataset, available at: http://mapas.igme.es/Servicios/default.aspx\#IGME_Permeabilidad_1M, last access: 20 October 5702021.

Lorenzo-Lacruz, J., Vicente-Serrano, S. M., López-Moreno, J. I., Morán-Tejeda, E., and Zabalza, J.: Recent Trends in Iberian Streamflows (1945-2005), J. Hydrol., 414-415, 463-475, https://doi.org/10.1016/j.jhydrol.2011.11.023, 2012. 
Lorenzo-Lacruz J, Vicente-Serrano SM, González-Hidalgo JC, López-Moreno JI, Cortesi N.: Hydrological drought response to meteorological drought in the Iberian Peninsula, Clim Res 58:117-131, https://doi.org/10.3354/cr01177, 2013.

Luo, D., \& Gong, T.: A possible mechanism for the eastward shift of interannual NAO action centers in last three decades, Geophysical research letters, 33(24). https://doi.org/10.1029/2006GL027860, 2006.

580 Massei, N., Kingston, D. G., Hannah, D. M., Vidal, J. P., Dieppois, B., Fossa, M., ... \& Laignel, B.: Understanding and predicting large-scale hydrological variability in a changing environment, Proceedings of the International Association of Hydrological Sciences, 383, 141-149. https://doi.org/10.5194/piahs-383-141-2020, 2020.

NOAA, The North Atlantic Oscillation Index, available at: 585 https://www.cpc.ncep.noaa.gov/products/precip/CWlink/pna/nao.shtml, last access: 20 October 2021.

Pohlert, T.: Trend: Non-parametric Trend Tests and Change-Point Detection, R package version 1.1.1, available at: https://CRAN.R-project.org/package=trend, last access: 20 October 2021

Polade, S.D., Gershunov, A., Cayan, D.R. et al.: Precipitation in a warming world: Assessing projected hydro-climate changes in California and other Mediterranean climate regions, Sci Rep 7, 10783, https://doi.org/10.1038/s41598-017-11285-y, 2017.

PSL, NCEP/NCAR Reanalysis 1 Repository, available at: https://psl.noaa.gov/data/gridded/data.ncep.reanalysis.html, last access: 20 October 2021.

R Core Team: A language and environment for statistical computing, R Foundation for Statistical Computing, at available at: https://rdrr.io/r/base/base-package.html, last access: 20 October 2021.

Schulzweida, U.: CDO user guide, Climate Data Operator, available at: https://code.mpimet.mpg.de/projects/cdo/embedded/index.html, last access: 20 October 2021.

Stahl, K., Hisdal, H., Hannaford, J., Tallaksen, L. M., van Lanen, H. A. J., Sauquet, E., Demuth, S., Fendekova, M., and Jódar, J.: Streamflow trends in Europe: evidence from a dataset of near-natural catchments, Hydrol. Earth Syst. Sci., 14, 2367-2382, https://doi.org/10.5194/hess-14-2367-2010, 2010. 
Teuling, A. J., de Badts, E. A. G., Jansen, F. A., Fuchs, R., Buitink, J., Hoek van Dijke, A. J., and Sterling, S. M.: Climate change, reforestation/afforestation, and urbanization impacts on evapotranspiration and streamflow in Europe, Hydrol. Earth Syst. Sci., 23, 3631-3652, https://doi.org/10.5194/hess-23-3631-2019, 2019.

Tramblay, Y., Llasat, M.C., Randin, C. et al.: Climate change impacts on water resources in the Mediterranean, Reg Environ Change, 20, 83, https://doi.org/10.1007/s10113-020-01665-y, 2020.

Trigo, R. M., Pozo-Vázquez, D., Osborn, T. J., Castro-Díez, Y., Gámiz-Fortis, S., \& Esteban-Parra, M. J.: North Atlantic oscillation influence on precipitation, river flow and water resources in the Iberian Peninsula, International Journal of Climatology, 24(8), 925-944, doi:10.1002/joc.1048, 2004.

Vicente-Serrano, S. M., Lopez-Moreno, J. I., Beguería, S., Lorenzo-Lacruz, J., Sanchez-Lorenzo, A., García-Ruiz, J. M., ... \& Espejo, F.: Evidence of increasing drought severity caused by temperature rise in southern Europe, Environmental Research Letters, 9(4), 044001, https://doi.org/10.1088/1748-9326/9/4/044001, 2014.

615 Vicente-Serrano, S. M., Peña-Gallardo, M., Hannaford, J., Murphy, C., Lorenzo-Lacruz, J., DominguezCastro, F., ... \& Vidal, J. P.: Climate, irrigation, and land cover change explain streamflow trends in countries bordering the northeast Atlantic, Geophysical Research Letters, 46(19), 10821-10833, https://doi.org/10.1029/2019GL084084, 2019.

Wang, Y. H., Magnusdottir, G., Stern, H., Tian, X., \& Yu, Y.: Uncertainty estimates of the EOF-derived North Atlantic Oscillation, Journal of climate, 27(3), 1290-1301. https://doi.org/10.1175/JCLI-D13-00230.1, 2014. 